\title{
Managing spondylotic cervical myeloradiculopathy using oblique cervical corpectomy
}

\author{
Abstract \\ Study design: A Prospective clinical case series study. \\ Objective: To evaluate the clinical and radiological outcomes of oblique \\ cervical corpectomy in the management of selected cases of Spondylotic Cervical \\ Myeloradiculopathy. \\ Methods: 18 patients with cervical spondylotic myeloradiculopathy were enrolled \\ in this study. Neurological function was graded by modified Japanese Orthopedic \\ Association scale, and the recovery rate was calculated. Both local symptoms and \\ radicular pain were evaluated using Visual Analog Scale. The minimum follow-up \\ period was 24 months.
}

Results: 12 males and 6 females with a mean age of 52 years underwent oblique cervical corpectomy with mean operative duration 172minutes. Mean Blood loss was $320 \mathrm{ml}$. Oblique corpectomy was done at a single level in 10 patients, two levels in 6 patients and three levels in 2 patients. There was a statistically significant improvement in both the mJOA scale and VAS for radicular symptoms. Postoperatively spine curvature in most of the cases remained unchanged. The development of straightening or kyphosis of the spine was not correlated with neurological weakness or worsening of clinical improvement. One case had intraoperative dural tear, three cases had postoperative Horner's syndrome that is temporary in two cases and persists in one.

Conclusion: Oblique corpectomy is a sound alternative to conventional central corpectomy and fusion in selected cases. By avoiding the use of implants and fusion, the procedure is cost effective with no fusion-related complications but is technically demanding.

Keywords: cervical myeloradiculopathy, cervical spine, oblique cervical corpectomy
Volume 10 Issue 4 - 2018

\author{
Ahmed Mohamed Elbadrawi, Tameem \\ Mohamed Elkhateeb \\ Department of Orthopedics and Spine Surgery, Faculty of \\ Medicine -Ain Shams University, Egypt
}

Correspondence: Tameem Mohamed Elkhateeb, Department of Orthopedics and Spine Surgery, Faculty of Medicine -Ain Shams University, Egypt, Email tameem_77@hotmail.com

Received: July 01, 2018| Published: August 09, 2018

\section{Introduction}

The procedure of oblique cervical corpectomy (OCC) illustrates maintenance of a considerable part of the ventral and lateral sides of the vertebral body. ${ }^{1}$ Ozer AF et al., ${ }^{2}$ reported a procedure and termed it "open window corpectomy" that is planned to eliminate the least quantity of bone and attain adequate decompression; using a highspeed drill and the surgical microscope, just the posterior surface of the vertebral body is eliminated after proper microdiscectomies. That leaves the ventral and the lateral parts of the vertebral body untouched. That oblique corpectomy didn't disturb the stability of the cervical spine and needs no stabilization. Karalar T et al., ${ }^{3}$ assumed an in vitro biomechanical investigation of multilevel OCC in sheep and stated that the technique doesn't cause instability of the spine. That method offers a roomy anterolateral decompression of the spinal canal and foramen at single or multiple levels, kyphotic spine isn't a contraindication if spinal stability is maintained, no demand for instrumentation and/or bone grafting, and very good exposure via lateral approach that is required in recurrent cases after prior anterior surgery. ${ }^{4}$ This study was done to evaluate the indications, efficiency, safety, and complications of OCC for the treatment of selected types of Spondylotic Cervical myeloradiculopathy.

\section{Materials and methods}

This is a prospective non-randomized clinical case series that was done between January 2009 and February 2014. It enrolled 18 cases who subjected to OCC for treatment of cervical spondylotic myeloradiculopathy. Cases were carefully chosen if they had cervical myelopathy \pm radiculopathy established by clinical data and CT scan and/or MRI with single or multiple level canal stenosis mostly as anterolateral compression. Cases were excluded if they had any instability or anterolisthesis $>2$ millimeters between any two contiguous vertebrae in dynamic views. Those criteria are like inclusion criteria listed in a series done by Salvatore et al. ${ }^{4}$ Also cases with ossified posterior longitudinal ligament were not included because of a basically another pathology, natural history, complication, and results. Every case in this series was carefully assessed clinically in the form of detailed history, complete neurological examination. A complete functional assessment was done by the Nurick score and a modified Japanese Orthopedic Association scale for cervical myelopathy (mJOA), and the postoperative recovery was estimated by the method proposed by Hirabayashi K et al. ${ }^{5}$

Post-op score - pre-op score $\div 17$ (full score) - pre-op score $\times 1005$

Visual analogue scale (VAS) was used for assessment of patient's pre and postoperative neck and radicular pain. An important part in the history focused on evaluation of the case by anesthesiologist to identify fitness and prerequisites of surgery. Radiological Evaluation: Plain X-rays of the cervical spine, including anteroposterior view, Flexion-Extension lateral views, and the standard lateral view. The canal dimensions and cord signal alterations are assessed by computerized tomography and MRI of the cervical spine. Just a short 
report of the procedure will be named because it has been delineated in detail before. ${ }^{6}$ The principle of the current procedure is built on that anterolateral compression of the cervical spinal cord and roots might be best treated by an anterolateral approach since it gives direct attack of the pathology. The approach is lateralized on the side of the radiculopathy or on the side of the most compressive elements. The patient in supine position. C-Arm is used to identify pathological levels. The dissection is tracked first medially to the medial border of the sternocleidomastoid muscle and then laterally to the lateral border of the carotid sheath. The muscle is retracted laterally, whereas the carotid sheath is medially displaced with a retractor blade to uncover the transverse processes of the cervical vertebrae. Beneath the aponeurosis of the longus colli muscle, the sympathetic chain should be identified. The aponeurosis is cut lateral to the sympathetic chain and then retracted medially with longus colli muscle (Figure 1).

After exposure the intervertebral discs above and below the pathological levels, the microscope is introduced. The discs are then resected up to the uncinate process laterally and disc-posterior osteophyte complex posteriorly. Uncinate process and posterior disc-osteophyte complex will be resected later after corpectomy is completed to get adequate working space for resection of both. By a cutting drill, oblique corpectomy is completed. The drilling starts in an oblique manner from the lateral side to the contrary posterolateral angle leaving around $2 \mathrm{~mm}$ of cortical bone on the lateral side of the vertebral body to secure the vertebral artery laterally. The posterior longitudinal ligament should be incised and as far as possible resected to establish ideal cord decompression (Figure 2). 24hours bed rest then patient ambulation was allowed in a soft cervical collar as tolerated. Postoperative x-ray was done. Patient discharged 72hours post-operative. Postoperative visits were scheduled at 2,6weeks then $3,6,12,18,24$ months. The patient is evaluated radiologically for stability, curvature, sagittal rotation and alignment. The Intraoperative complication, blood loss, operative period and hospital stay were documented to each case.

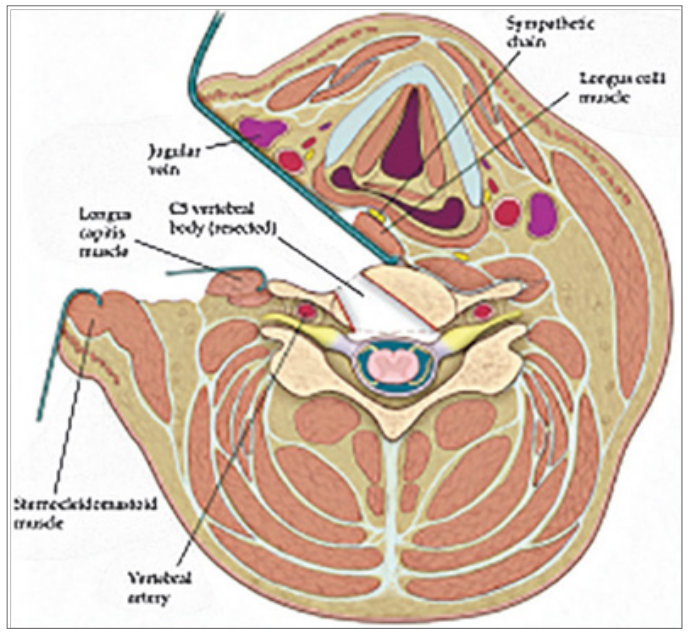

Figure I Diagram displaying the dissection plane. ${ }^{6}$

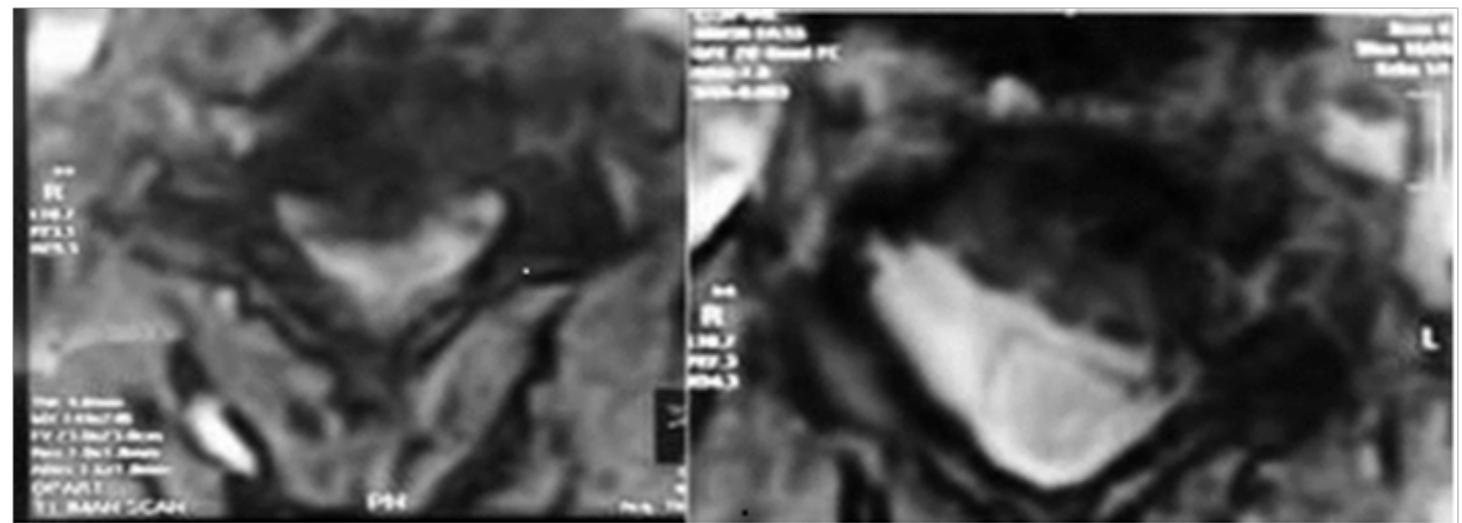

Figure 2 Pre and Post-operative axial MRI displaying spinal canal decompression after one level OCC.

\section{Results}

Eighteen cases (12 males, 6 females) with a mean age of 52.4 years \pm 9 (SD). The average duration of symptoms was $14 \pm 10.5$ (SD)months. All patients suffered from radicular symptoms, neck pain, and motor weakness. A total of 28 level were decompressed, (C3$\mathrm{C} 4$ in 2, C4-C5 in 9, C5-C6 in 12, C6-C7 in 5) Oblique corpectomy was done at a single level in 10 cases, two levels in 6 cases and three levels in 2 cases. The mean operative duration was 172 minutes \pm 19.9 (SD). The mean operative blood loss was $319.8 \mathrm{ml} \pm 111.2$ (SD). The follow-up period in this series varied from 24 to 42 months with a mean of 32 months \pm 2.92 (SD). The mean pre-operative mJOA scale of patients was 8.12 points \pm 3.11 (SD) while the mean post-operative mJOA scale was 15.12 points $\pm 1.53(\mathrm{SD})$. The recovery rate was
$70.91 \%$. The mean preoperative VAS for axial symptoms was $2.2 \pm 1.3$ (SD) while the mean postoperative VAS was $2.4 \pm 1.2 \mathrm{SD}(\mathrm{p}>0.05)$. Mean preoperative VAS for radicular symptoms was $7.2 \pm 1,2 \mathrm{SD}$ and improved to mean postoperative VAS of $4.1 \pm 1.3 \mathrm{SD}(\mathrm{p}<0.05)$. There was statistically significant improvement in the mean post-operative mJOA scale and Mean post-operative VAS for radicular symptoms in such cases as compared to the mean pre-operative values $(\mathrm{p}<0.05)$. Radiologically pre-operative; 6 cases had a normal cervical lordotic curve, 10 cases had a straight cervical spine and 2 cases had a reversed cervical curve. Postoperatively spine curvature in most of the cases remained unchanged. The development of straightening or kyphosis of the spine was not correlated with neurological weakness or worsening of clinical improvement. In this series, one case experienced intraoperative dural tear with cerebrospinal fluid leakage 
and managed effectively during the surgery using Dural patching, three cases had Horner's syndrome that is temporary in two cases and symptoms noticeably settled within 4 months, the other case persists but improving with physiotherapy. No recurrence, segmental instability, Kyphosis progression nor vertebral body collapse was noticed throughout the follow-up.

\section{Discussion}

Males account for most of the cases in this series with 33\% being females. Most studies show slight male preponderance. ${ }^{4,7,8}$ Mean age of 52years in this series is slightly lesser than that apparent in other studies $^{4,6,9}$ and this can be explained that other studies like George B et al., ${ }^{6}$ described hard, collapsed discs in Spondylotic Cervical Myeloradiculopathy that tend to happen in the elder age group. Oldness did not associate with results in this study, an outcome that is reinforced by most of the reviews. ${ }^{9,10}$ Furthermore, this study shows that MRI intramedullary variations, number of levels worked on, symptoms duration did not expect the outcome. These results confirm the conclusion of the study done by Chacko AG et al., ${ }^{11}$ in 2012 reviewing 109 patients. Though several researchers are not emphasized with intramedullary MRI variations as a predictor of the result, some authors propose that $\mathrm{T} 1$ hypointense zone along with $\mathrm{T} 2$ hyperintense zone within the cord, especially if multi-segment are correlated with bad results. ${ }^{12,13}$ Concerning median corpectomy and fusion; The risk of graft-site complications varies from $8 \%$ to $28 \%{ }^{14}$ Fusion associated accelerated degenerative changes in the adjacent segment taking place from 26 to $82 \%$ in several long-term studies. ${ }^{15,16}$ Median corpectomy more than two levels be susceptible to kyphosis postoperative and implant loosening provoking surgeons to perform further stabilization in these cases. ${ }^{8}$

Studies on the OCC have recognized that the procedure gives good outcomes verified by clinical result measures for myelopathy and radiological evaluation of spinal alignment. ${ }^{7,10,17}$ The most important benefit to this procedure is the sufficient anterior decompression without the necessity for bony fusion; no necessity for bone grafting and/or instrumentation making it very appropriate for old persons and economic. Furthermore, Chacko AG et al., ${ }^{11}$ have revealed that after OCC there is motion preservation in the worked segment at short period follow-up that is larger for longer segments of decompression. So far, data relating to the preserving motion in the long-term is insufficient and continues to be existed. Compared to other studies, this study had nearly the same recovery rate $(71.08 \%)$ that is detected in other reviews with $\mathrm{OCC}^{4,6,7,10,17}$ and the median corpectomy. $8,14,18,19$ Kiris $\mathrm{T}$ et al., ${ }^{20}$ considered the mJOA score results in 40 patients with cervical spondylotic myelopathy who went through oblique cervical corpectomy. There was an improvement in 37 cases $(92.5 \%)$ at the 6 month follow-up period. Bruneau $\mathrm{M}$ et al., ${ }^{21}$ stated their outcomes in 100 cases that revealed improvement in $82 \%$ of their cases. In this study, there was a statistically significant improvement in the JOAS and VAS for radicular symptoms. Regarding whole spine curvature after OCC, in their series, Kiris $\mathrm{T}$ et al., ${ }^{20}$ revealed that sagittal alignment was well-maintained at a mean of 59months follow-up period. Chacko AG et al. stated of the 117 cases who had a lordotic or straight spine preoperatively, only 5 cases got an asymptomatic kyphosis at last follow-up, while $80 \%$ of the straight spines was well preserved reflecting a sensible preservation of sagittal alignment. This is highly comparable to the results of this study. Even though the OCC was considered more than tenyears before, ${ }^{6}$ it has not expanded perhaps because of the challenging procedure associated with handling the sympathetic chain and related Horner's syndrome along with the hazard of accidental injury of the vertebral artery. In this study, only one case was complicated by permanent Horner's syndrome (5.6\%), which is comparable to other studies. ${ }^{4,7,10,17,18}$ The other two cases were a transient observed in the early postoperative time. In this study, we spotted the sympathetic chain and the stellate ganglion. The aponeurosis is cut lateral to the sympathetic chain and retracted medially with the medial two-thirds of longus colli muscle. Very well understanding of vertebral artery anatomy and its variance is crucial in doing this surgery and that watchful assessment of preoperative MRI and/or MRA is essential. Lastly, we would like to stress that this technique is a demanding procedure with a steep learning curve., it is essential to do the surgery by an experienced surgeon. This study had several limitations: First: the small number of the patient. Second: no control group of alternative surgical approaches. Third: the follow up was an intermediate term only.

\section{Conclusion}

OCC is a valid another technique for treatment of multi-segmental cervical spondylotic myelopathy that maintains stability without instrumentation or bone grafting. It also allows early mobilization. Optimum outcomes count on the meticulous choice of cases and maintenance of cervical spine stability.

\section{Acknowledgements}

None.

\section{Conflict of interest}

Author declares that there is no conflict of interest.

\section{References}

1. Wada E, Suzuki S, Kanazawa A, et al. Subtotal corpectomy versus laminoplasty for multilevel cervical spondylotic myelopathy: a long-term follow-up study over 10years. Spine (Phila Pa 1976). 2001;26(13):1443-1447.

2. Ozer AF, Oktenoğlu BT, Sarioğlu AC. A new surgical technique: openwindow corpectomy in the treatment of ossification of the posterior longitudinal ligament and advanced cervical spondylosis: technical note. Neurosurgery. 1999;45(6):1481-1485.

3. Karalar T, Unal F, Güzey FK, et al. Biomechanical analysis of cervical multilevel oblique corpectomy: an in vitro study in sheep. Acta Neurochir (Wien); 2004;146(8):813-818.

4. Chibbaro S, Mirone G, Makiese O, et al. Multilevel oblique corpectomy without fusion in managing cervical myelopathy: long-term outcome and stability evaluation in 268 patients. J Neurosurg Spine. 2009;10(5):458465

5. Hirabayashi K, Miyakawa J, Satomi K, et al. Operative results and postoperative progression of ossification among patients with ossification of cervical posterior longitudinal ligament. Spine. 1981;6(4):354-364.

6. George B, Gauthier N, Lot G. Multisegmental cervical spondylotic myelopathy and radiculopathy treated by multilevel oblique corpectomies without fusion. Neurosurgery. 1991;44(1):81-90.

7. Chacko AG, Turel MK, Sarkar S, et al. Clinical and radiological outcomes in 153 patients undergoing oblique corpectomy for cervical spondylotic myelopathy. Br J Neurosurg. 2014;28(1):49-55. 
8. Gok B, Sciubba DM, McLoughlin GS, et al. Surgical treatment of cervical spondylotic myelopathy with anterior compression: a review of 67 cases. J Neurosurg Spine. 2008;9(2):152-157.

9. Yamazaki T, Yanaka K, Sato H, et al. Cervical spondylotic myelopathy: surgical results and factors affecting outcome with special reference to age differences. Neurosurgery. 2003;52(1):122-126.

10. Rocchi G, Caroli E, Salvati M, et al. Multilevel oblique corpectomy without fusion: our experience in 48 patients. Spine. 2005;30(17):19631969.

11. Chacko AG, Joseph M, Turel MK, et al. Multilevel oblique corpectomy for cervical spondylotic myelopathy preserves segmental motion. Eur Spine J. 2012;21(7):1360-1367.

12. Alafifi T, Kern R, Fehlings M. Clinical and MRI predictors of outcome after surgical intervention for cervical spondylotic myelopathy. $J$ Neuroimaging. 2007;17(4):315-322.

13. Mastronardi L, Elsawaf A, Roperto R, et al. Prognostic relevance of the postoperative evolution of intramedullary spinal cord changes in signal intensity on magnetic resonance imaging after anterior decompression for cervical spondylotic myelopathy. J Neurosurg Spine. 2007;7(6):615-622.

14. Fessler RG, Steck JC, Giovanini MA. Anterior cervical corpectomy for cervical spondylotic myelopathy. Neurosurgery. 1998;43(2):257-265.
15. Kulkarni V, Rajshekhar V, Raghuram L. Accelerated spondylotic changes adjacent to the fused segment following central cervical corpectomy: magnetic resonance imaging study evidence. J Neurosurg. 2004;100 (1 Suppl Spine):2-6.

16. Dmitriev AE, Cunningham BW, Hu N, et al. Adjacent level intradiscal pressure and segmental kinematics following a cervical total disc arthroplasty: An in vitro human cadaveric model. Spine. 2005;30(10):11651172 .

17. Koc RK, Menku A, Akdemir H, et al. Cervical spondylotic myelopathy and radiculopathy treated by oblique corpectomies without fusion. Neurosurg Rev. 2004;27(4):252-258.

18. Rajshekhar V, Muliyil J. Patient perceived outcome after central corpectomy for cervical spondylotic myelopathy. Surg Neurol. 2007;68(2):185-190.

19. Saunders RL, Bernini PM, Shirreffs TG Jr, et al. Central corpectomy for cervical spondylotic myelopathy: a consecutive series with long-term follow-up evaluation. $J$ Neurosurg. 1991;74(2):163-170.

20. Kiris T, Kilinçer C. Cervical spondylotic myelopathy treated by oblique corpectomy: a prospective study. Neurosurgery. 2008;62(3):674-682.

21. Bruneau M, Cornelius JF, George B. Multilevel oblique corpectomies: surgical indications and technique. Neurosurgery. 2007;61(3 Suppl):106-112. 